\title{
Management Strategies for Follicular Lymphoma patients in Remission after Modern Frontline Chemoimmunotherapies
}

Lubna Chaudhary ${ }^{1}$ and Mehdi Hamadani ${ }^{2 *}$

${ }^{1}$ Myeloma and Lymphoma Program, Section of Hematology and Oncology, West Virginia University, WV, USA

${ }^{2}$ Division of Hematology and Oncology, West Virginia University, WV, USA

Keywords: Follicular lymphoma; Rituximab; Maintenance; Consolidation

Follicular lymphoma (FL) is the second most common type of nonHodgkin lymphoma [1]. The development of rituximab represented a major breakthrough in the management of FL, with several landmark clinical trials consistently demonstrating superior survival outcomes with rituximab-containing chemoimmunotherapies compared to chemotherapy alone, both in the frontline [2-5] and relapsed/ refractory settings [6]. However despite the remarkable advances in chemoimmunotherapy for FL, these modalities are still not considered curative, hence; strategies designed to extend remission duration is often a key therapeutic goal. Nearly all FL patients treated with first line chemoimmunotherapies will eventually relapse. The currently available options to extend the duration of first remission and possibly survival outcomes in FL include; consolidation with autologous transplantation, maintenance rituximab (MR), radioimmunotherapy (RIT) consolidation and rituximab retreatment (RRT). In this editorial we provide a brief overview of how to approach a patient with FL in remission following first line modern chemoimmunotherapies.

Five randomized clinical trials have examined the role of autologous transplantation for consolidating FL patients in first remission, both in the pre-rituximab [7-10], and rituximab eras [9]. Unfortunately; while none of these trials were able to demonstrate an overall survival (OS) benefit with autologous transplantation, this modality was associated with a significantly higher risk of secondary myelodysplastic syndrome, acute myeloid leukemia [7], and second malignancies [10]. While keeping in perspective the recent advances in the management of FL, including RIT consolidation [11], MR [12], or RRT [13], the routine use of autologous transplantation for FL in first remission is not recommended, especially considering its associated risk of secondary malignancies, and the lack of a clear OS benefit.

Several prospective studies have evaluated the role of MR for FL patients in remission after frontline therapies (Table 1). The ECOG

\begin{tabular}{|c|c|c|c|c|}
\hline $\begin{array}{l}\text { Author } \\
\text { (Year) }\end{array}$ & $\begin{array}{l}\text { No. of } \\
\text { patients }\end{array}$ & $\begin{array}{l}\text { Maintenance } \\
\text { schedule }\end{array}$ & $\begin{array}{l}\text { PFS or EFS } \\
\text { (MR vs. } \\
\text { observation) }\end{array}$ & $\begin{array}{l}\text { OS (MR vs. } \\
\text { Observation) }\end{array}$ \\
\hline $\begin{array}{l}\text { Hochster } \\
2009 \text { [14] }\end{array}$ & 387 & $\begin{array}{c}\text { Four weekly doses } \\
\text { every } 6 \text { months for } \\
2 \text { years }\end{array}$ & $\begin{array}{c}64 \% * \text { vs. } 33 \% \\
(3 \text { years })\end{array}$ & $\begin{array}{c}91 \% \text { vs. } 86 \% \text { (3 } \\
\text { years) }\end{array}$ \\
\hline $\begin{array}{l}\text { Martinelli } \\
2010[16]\end{array}$ & 202 & $\begin{array}{l}\text { Single dose at } 3,5 \text {, } \\
7 \text { and } 9 \text { months }\end{array}$ & $\begin{array}{c}24 \text { months* }^{*} \text { vs. } \\
13 \text { months }\end{array}$ & $\begin{array}{l}\text { Difference not } \\
\text { statistically } \\
\text { significant }\end{array}$ \\
\hline $\begin{array}{c}\text { Salles } \\
2011[12]\end{array}$ & 1217 & $\begin{array}{l}\text { Single dose every } 2 \\
\text { months for } 2 \text { years }\end{array}$ & $\begin{array}{c}75 \%{ }^{*} \text { vs. } 58 \% \\
\text { (3 years) }\end{array}$ & $\begin{array}{l}\text { Not significantly } \\
\text { different between } \\
\text { the two arms }\end{array}$ \\
\hline $\begin{array}{c}\text { Vitolo } \\
2011[15]\end{array}$ & 242 & $\begin{array}{l}\text { Single dose every } 2 \\
\text { months for } 4 \text { doses }\end{array}$ & $\begin{array}{c}80 \% \text { versus } \\
68 \% \\
\text { (2 years) }\end{array}$ & No data available \\
\hline
\end{tabular}

Abbreviations: MR: Maintenance Rituximab; OS: Overall Survival; PFS: Progression Free Survival

*Statistically significant value

Table 1: Maintenance of rituximab in patients with follicular lymphoma after frontline therapies.
(Eastern Cooperative Oncology Group) 1496 trial randomized 311 indolent NHL patients after frontline chemotherapy with cyclophosphamide, vincristine and prednisone to either MR or observation [14]. MR in this study was associated with a longer progression-free survival (PFS) but no OS advantage was seen. However; since patients in the ECOG 1496 study did not receive rituximab in combination with induction chemotherapy, the results of this trial cannot be extrapolated to patients receiving rituximabcontaining induction chemoimmunotherapies. The role of MR in patients receiving rituximab-based induction chemoimmunotherapies was addressed in the recently published PRIMA study [12], where MR when compared to observation alone, was associated with higher response rates, improved PFS, but no OS benefit [12]. It is important to note that MR in PRIMA study was not able to improve quality of life (QOL). In the preliminary results of Italian Lymphoma Foundation (ILF) trial, a brief course of MR after a fludarabine-based chemoimmunotherapy induction was not able to significantly prolong PFS, when compared with patients in the observation arm [15]. The short rituximab maintenance schedule used in ILF study is likely responsible for this lack of PFS benefit. Considering the collective data summarized in table 1, in FL patients responding to frontline induction chemoimmunotherapies, MR appears to be a reasonable option. When offering this therapy to a potential patient the associated healthcare costs, possible increase in adverse events, and the lack of an OS benefit or improved QOL must be taken into consideration.

A potential alternative to $M R$ is re-treatment with rituximab at the time of relapse. Potential advantages of a retreatment strategy include administration of fewer rituximab doses, potentially lower healthcare costs, and possibly fewer infectious complications. The ECOG recently presented the preliminary results of the RESORT trial in the 2011 annual meetings of American Society of Hematology [13]. The RESORT study was designed to compare MR against RRT in the frontline setting. In this study $284 \mathrm{FL}$ patients responding to four weekly doses of rituximab were randomly assigned to either MR or RRT at progression (four weekly rituximab doses). At a median followup of 3.8 years, time to treatment failure (defined as disease progression within 6 months of the last rituximab dose) was not significantly different between the two arms (3.9 years for MR vs. 3.6 years for RRT).

${ }^{*}$ Corresponding author: Mehdi Hamadani, M.D., Division of Hematology and Oncology, West Virginia, University, 1 Medical Center Drive, Morgantown, WV 26506, USA, Tel: 304-598-4000; Fax: 304-598-4522; E-mail: mehdi.hamadani@gmail.com

Received November 02, 2012; Accepted November 03, 2012; Published November 05, 2012

Citation: Chaudhary L, Hamadani M (2013) Management Strategies for Follicula Lymphoma patients in Remission after Modern Frontline Chemoimmunotherapies. J Blood Disorders Transf 4:e105. doi:10.4172/2155-9864.1000e105

Copyright: (c) 2013 Chaudhary L, et al. This is an open-access article distributed under the terms of the Creative Commons Attribution License, which permits unrestricted use, distribution, and reproduction in any medium, provided the original author and source are credited. 
While significantly more patients in the MR arm were free of cytotoxic chemotherapy at 3 years (95\% vs. $86 \%)$, this was achieved at the cost of three times greater use of rituximab in the maintenance cohort. Most importantly MR was not able to demonstrated better QOL, reduced anxiety, or fewer infectious complications. The remarkable findings of RESORT trial that RRT maintains patient QOL, and that it is associated with significantly less rituximab use has important ramifications for current clinical practice. At our specialized Myeloma and Lymphoma Service at the West Virginia University, we prefer RRT over MR for FL patients (particularly the subset with low bulk disease) following frontline immune- or chemoimmunotherapies.

Another option, with the potential to extend remission duration in FL is RIT consolidation (e.g. with yttrium-90-ibritumomab tiuxetan (Zevalin)). In randomized study of 414 FL patients, RIT consolidation with Zevalin significantly prolonged median PFS (36.5 v 13.3 months in control arm), but without any clear OS benefit (11). The most common toxicities with RIT were hematologic and grade 3 or 4 infections. No randomized studies to our knowledge have compared RIT against MR or RRT in FL. Since administration of RIT is typically only feasible in academic medical centers or larger private practices equipped with nuclear medicine facilities capable of handling radioisotopes/ biohazards, and also secondary to the relatively long neutrophil nadirs following Zevalin therapy, widespread use of this consolidation modality is limited in current clinical practice.

The outcomes of patients with FL have dramatically improved over the last decade, owing mainly to the addition of immunotherapy with rituximab in the therapy armamentarium. Ongoing clinical trials in the coming years will hopefully clarify the pros and cons of longer (4-5 years) and shorter (<1year) MR schedules, compared to the standard 2 year schedule used currently (NCT00877214 and NCT00227695; www. clinicaltrials.gov). Whether the results of maintenance therapy can be improved by incorporating chemo- or immunotherapeutic agents also warrants prospective investigation. The ongoing ECOG 2408 protocol is examining the role MR with or without lenalidomide in newly diagnosed FL (NCT01216683). Continued prospective trials in the coming years will hopefully clarify the best therapeutic modality for FL in first remission after frontline chemoimmunotherapies.

No financial and personal conflicts of interest to disclose.

\section{References}

1. Ayala E, Tomblyn M (2011) Hematopoietic cell transplantation for lymphomas. Cancer Control 18: 246-257.

2. Marcus R, Imrie K, Solal-Celigny P, Catalano JV, Dmoszynska A, et al. (2008) Phase III study of R-CVP compared with cyclophosphamide, vincristine, and prednisone alone in patients with previously untreated advanced follicular lymphoma. J Clin Oncol 26: 4579-4586.

3. Hiddemann W, Kneba M, Dreyling M, Schmitz N, Lengfelder E, et al. (2005) Frontline therapy with rituximab added to the combination of cyclophosphamide doxorubicin, vincristine, and prednisone (CHOP) significantly improves the outcome for patients with advanced-stage follicular lymphoma compared with therapy with $\mathrm{CHOP}$ alone: results of a prospective randomized study of the German Low-Grade Lymphoma Study Group. Blood 106: 3725-32.

4. Herold M, Haas A, Srock S, Neser S, Al-Ali KH, et al. (2007) Rituximab added to first-line mitoxantrone, chlorambucil, and prednisolone chemotherapy followed by interferon maintenance prolongs survival in patients with advanced follicular Iymphoma: An east german study group hematology and oncology study. J Clin Oncol 25: 1986-1992.

5. Salles G, Mounier N, de Guibert S, Morschhauser F, Doyen C, et al. (2008) Rituximab combined with chemotherapy and interferon in follicular lymphoma patients: results of the GELA-GOELAMS FL2000 study. Blood 112: 4824-4831.
6. Forstpointner R, Dreyling M, Repp R, Hermann S, Hänel A, et al. (2004) The addition of rituximab to a combination of fludarabine, cyclophosphamide mitoxantrone (FCM) significantly increases the response rate and prolongs survival as compared with FCM alone in patients with relapsed and refractory follicular and mantle cell lymphomas: Results of a prospective randomized study of the german low-grade lymphoma study group. Blood 104: 3064-3071.

7. Lenz G, Dreyling M, Schiegnitz E, Forstpointner R, Wandt H, et al. (2004) Myeloablative radiochemotherapy followed by autologous stem cell transplantation in first remission prolongs progression-free survival in follicular lymphoma: Results of a prospective, randomized trial of the german low-grade lymphoma study group. Blood 104: 2667-2674.

8. Sebban C, Mounier N, Brousse N, Belanger C, Brice P, et al. (2006) Standard chemotherapy with interferon compared with $\mathrm{CHOP}$ followed by high-dose therapy with autologous stem cell transplantation in untreated patients with advanced follicular lymphoma: the GELF-94 randomized study from the Groupe d'Etude des Lymphomes de l'Adulte (GELA). Blood 108: 2540-2544.

9. Ladetto M, De Marco F, Benedetti F, Vitolo U, Patti C, et al. (2008) Prospective, multicenter randomized GITMO/IIL trial comparing intensive (R-HDS) versus conventional (CHOP-R) chemoimmunotherapy in high-risk follicular lymphoma at diagnosis: The superior disease control of R-HDS does not translate into an overall survival advantage. Blood 111: 4004-4013.

10. Gyan E, Foussard C, Bertrand P, Michenet P, Le Gouill S, et al. (2009) High-dose therapy followed by autologous purged stem cell transplantation and doxorubicin-based chemotherapy in patients with advanced follicular lymphoma: a randomized multicenter study by the GOELAMS with final results after a median follow-up of 9 years. Blood 113: 995-1001.

11. Morschhauser F, Radford J, Van Hoof A, Vitolo U, Soubeyran P, et al. (2008) Phase III trial of consolidation therapy with yttrium-90-ibritumomab tiuxetan compared with no additional therapy after first remission in advanced follicular lymphoma. J Clin Oncol 26: 5156-5164.

12. Salles G, Seymour JF, Offner F, López-Guillermo A, Belada D, et al. (2011) Rituximab maintenance for 2 years in patients with high tumour burden follicula lymphoma responding to rituximab plus chemotherapy (PRIMA): a phase 3 , randomised controlled trial. Lancet 377: 42-51

13. Kahl BS, Hong F, Williams M, Gascoyne RD, Wagner LI, et al. (2011) Results of eastern cooperative oncology group protocol E4402 (RESORT): A randomized phase III study comparing two different rituximab dosing strategies for low tumor burden follicular lymphoma. Blood 118: LBA-6.

14. Hochster H, Weller E, Gascoyne RD, Habermann TM, Gordon LI, et al. (2009) Maintenance rituximab after cyclophosphamide, vincristine, and prednisone prolongs progression-free survival in advanced indolent lymphoma: results of the randomized phase III ECOG1496 Study. J Clin Oncol 27: 1607-1614.

15. Vitolo U, Ladetto M, Boccomini C, Evangelista A, Gamba E, et al. (2011) Brief chemoimmunotherapy R-FND with rituximab consolidation followed by randomization between rituximab maintenance vs. observation as first line treatment in elderly patients with advanced follicular lymphoma (FL): Final results of a prospective randomized trial by italian lymphoma foundation (FIL). Blood 118: 777.

16. Martinelli AB, DE Moraes-Barros N, Alvarenga CS, Chaves PB, Santos LA, et al. (2010) A PCR-RFLP assay for gender assignment in the three-toed sloths (Bradypus, Pilosa, Bradypodidae). Mol Ecol Resour 10: 732-4. 